\title{
Desempenho e parâmetros nutricionais de fêmeas leiteiras em crescimento alimentadas com silagem de milho ou cana-de-açúcar com concentrado ${ }^{1}$
}

\author{
Adriano Henrique do Nascimento Rangel ${ }^{2 *}$, José Maurício de Souza Campos ${ }^{3}$, André Soares \\ de Oliveira ${ }^{2}$, Sebastião de Campos Valadares Filho ${ }^{3}$, Anderson Jorge de Assis ${ }^{2}$, Shirley Motta \\ de Souza ${ }^{2}$
}

1 Projeto financiado pelo CNPq.
2 Programa de Pós-graduação em Zootecnia - UFV.
${ }^{3}$ Departamento de Zootecnia/UFV. Bolsita do CNPq.

RESUMO - Avaliou-se a resposta de novilhas leiteiras alimentadas com dieta à base de silagem de milho e com 1,3 kg/dia de concentrado em comparação a três dietas à base de cana-de-açúcar corrigida com 1\% de ureia + sulfato de amônio (9:1) (ureia), com 1,3; 2,0 e 2,7 kg/dia de concentrado. Foram utilizadas 20 novilhas (12 da raça Holandesa e oito da raça Pardo-Suíça) em delineamento de blocos casualizados, com cinco blocos formados de acordo com o peso inicial e a raça dos animais. Os consumos de matéria seca, matéria orgânica e fibra detergente neutro não diferiram entre a dieta à base de silagem de milho e aquelas à base de cana-de-açúcar. Maior consumo de extrato etéreo foi observado quando fornecida a dieta à base de silagem de milho em comparação àquelas à base de cana-de-açúcar. Os consumos de carboidratos totais e carboidratos não-fibrosos diferiram entre a dieta com silagem de milho e as dietas à base de cana-de-açúcar (1,3 e 2,0 kg de concentrado). O consumo de nutrientes digestíveis totais observado com o fornecimento da dieta à base de silagem de milho foi menor que o obtido com a cana-de-açúcar (2,0 kg de concentrado). As dietas tiveram efeito significativo nos coeficientes de digestibilidade de proteína bruta, extrato etéreo, carboidratos totais e fibra em detergente neutro. Não houve diferença significativa no ganho de peso total nem no ganho médio diário entre a dieta à base de silagem de milho e aquela à base de cana-de-açúcar com 2,7 kg de concentrado em relação às dietas com cana-de-açúcar. O pH ruminal não diferiu nos tempos de coleta entre as dietas experimentais. A concentração de nitrogênio amoniacal mais baixa foi observada 3 horas após a alimentação nos animais alimentados com dieta à base de silagem de milho. A cana-de-açúcar corrigida e com maior participação de concentrado (relação volumoso:concentrado \pm 45 :55, na base seca da dieta) pode ser utilizada em substituição à silagem de milho em sistemas de produção de leite com idade ao parto próxima dos 24 meses.

Palavras-chave: novilhas leiteiras, $\mathrm{pH}$ ruminal, ureia

\section{Performance and nutritional parameters of growing heifers fed corn silage or sugar cane with concentrate}

\begin{abstract}
This study evaluated the response of dairy heifers fed corn based silage with $1.3 \mathrm{~kg} /$ day of concentrated in comparison with three sugar cane-based diets corrected with $1 \%$ of urea + ammonium sulphate (9:1) (urea), with 1.3 ; 2.0 and $2.7 \mathrm{~kg}$ /day of concentrate. A total of 20 heifers were used (12 Holstein breed and 8 Brown Swiss breed heifers) in a randomised block design, with 5 blocks formed on the basis of initial live weight and breed. The consumption of dry matter, organic matter and neutral detergent fiber did not differ between corn-silage based diet and sugar-cane based diet. Higher consumption of ether extract was found when diet based on corn silage was supplied in comparison to those based on sugar cane. Intakes of total carbohydrate and non-fibrous carbohydrates differed between corn silage diet and those based on sugarcane (1.3 and $2.0 \mathrm{~kg}$ concentrate). Total digestible nutrient intake observed with supply of the diet based on corn silage was lower than that obtained with sugar cane ( $2 \mathrm{~kg}$ concentrate). Diets had a significant effect on coefficients of digestibility of crude protein, ether extract, total carbohidrates and neutral detergent fiber. There was no significant difference on total weight gain neither on average daily gain between the corn-silage based diet and the sugar-cane diet with $2.7 \mathrm{~kg}$ of concentrate in relation to the sugar-cane diets. Ruminal $\mathrm{pH}$ did not differ at collection times among experimental diets. The lowest concentration of $\mathrm{N}-\mathrm{NH}_{3}$ was observed in animals fed corn silage-based diet 3 hours after feeding compared to the sugar cane-based treatments. A milk production system with heifers calving at 24 months and fed a diet containing moderate to high concentrate levels ( \pm 45:55, forage:concentrate), sugar cane forage added with $1 \%$ of a mixture of urea + ammonium sulfate (9:1, urea:ammonium sulphate) can be a substitute for corn silage.
\end{abstract}

Key Words: dairy heifers, ruminal $\mathrm{pH}$, urea 


\section{Introdução}

A alimentação, além de preponderante em qualquer sistema de produção, contribui com uma parcela significativa dos custos de criação. Com vistas à solução desse problema, tem-se buscado alternativas para redução dos custos e que mantenham a produção do rebanho satisfatória. O uso de alimentos alternativos nos sistemas produtivos tem contribuído para diluição dos custos e aumento da sustentabilidade dos sistemas.

O uso de cana-de-açúcar na alimentação de ruminantes tem importância cada vez maior no Brasil, tendo em vista a redução do custo da alimentação sem perdas expressivas no desempenho animal. Em sistemas de produção bovina, tanto de leite quanto de corte, tem-se utilizado a cana-deaçúcar em substituição às silagens de milho e sorgo, fontes de alimentos volumosos mais utilizadas. Entretanto, as limitações nutricionais dessa forrageira, como o baixo teor de proteína, fibra de baixa degradação ruminal, aumento na quantidade de protozoários no rúmen e desbalanço de minerais, têm limitado seu uso em sistemas de produção de leite de maior nível de manejo e alimentação. Assim, sua utilização em sistemas de menor nível de manejo e alimentação tem sido prática de suplementação comum no período da seca (Preston, 1982; Balsalobre et al., 1999).

Neste contexto, tem crescido o interesse entre técnicos e produtores no aproveitamento dessa forrageira em sistemas de produção de leite de maior produtividade e na recria de animais leiteiros com idade ao primeiro parto próxima de 24 meses. Resultados favoráveis à utilização da cana-de-açúcar foram encontrados nos trabalhos de Magalhães et al. (2006), Mendonça et al (2004), Corrêa et al. (2003), Sousa et al. (2009), Costa et al. (2005) e Oliveira et al. (2007) com vacas leiteiras e Andrade \& Pereira (1999) e Gallo et al. (2000) com novilhas leiteiras, caracterizando o enorme potencial do uso de cana-de-açúcar em dietas balanceadas para ruminantes.

Nesse sentido desenvolveu-se este trabalho com o objetivo de avaliar o consumo, a digestibilidade aparentes dos nutrientes, os parâmetros ruminais, a concentração de ureia no soro, o desempenho e a economicidade de dietas contendo cana-de-açúcar com concentrado nos níveis de 1,$3 ; 2,0$ ou 2,7 kg/dia em comparação a uma dieta à base de silagem de milho com 1,3 kg/dia de concentrado em fêmeas leiteiras em crescimento.

\section{Material e Métodos}

O experimento foi desenvolvido na Unidade de Ensino, Pesquisa e Extensão em Gado de Leite (UEPE-GL) do Departamento de Zootecnia da Universidade Federal de Viçosa, no período de março a junho de 2004. A cidade de Viçosa localiza-se na Região da Zona da Mata no Estado de Minas Gerais e tem como coordenadas geográficas a posição $20^{\circ} 45^{\prime} 20^{\prime \prime}$ de latitude sul e $45^{\circ} 52^{\prime} 40^{\prime \prime}$ de longitude oeste de Greenwich e altitude de $651 \mathrm{~m}$. O clima da região é do tipo Cwa (mesotérmico), segundo a classificação de Köppen, e apresenta duas estações bem definidas, com verões quentes e úmidos e invernos frios e secos. A precipitação pluviométrica média é de 1.341,2mm anuais e as médias de temperaturas máximas e mínimas são 26,1 e $14,0^{\circ} \mathrm{C}$, respectivamente (UFV, 1997b).

Foram utilizadas 20 novilhas leiteiras (12 da raça Holandesa e 8 da raça Pardo-Suíça), com peso médio inicial de $176 \mathrm{~kg}$. O delineamento experimental adotado foi em blocos casualizados, com cinco blocos, considerando cada animal uma unidade experimental e os blocos formados de acordo com o peso inicial e a raça dos animais.

Os animais foram alimentados com três dietas à base de cana-de-açúcar corrigida com $1 \%$ de ureia + sulfato de amônia (9:1) (ureia) e concentrado nos níveis de 1,3; 2,0; e $2,7 \mathrm{~kg} /$ dia em comparação a uma dieta à base de silagem de milho com 1,3 kg/dia de concentrado. A relação volumoso:concentrado correspondeu, no início do experimento, a 75:25, 60:40 e 45:55, respectivamente, para cada nível de concentrado adicionado à cana-de-açúcar corrigida e a 75:25 na dieta à base de silagem de milho (Tabela 1). As dietas foram isoproteicas (Tabela 2) e formuladas para atender às exigências de novilhas leiteiras para ganho de peso corporal de $0,800 \mathrm{~kg} / \mathrm{dia}$ (NRC, 2001).

Tabela 1 - Proporção dos ingredientes nos concentrados (\%MS)

\begin{tabular}{|c|c|c|c|c|}
\hline & \multicolumn{4}{|c|}{ Nível de concentrado na dieta (kg/animal/dia) } \\
\hline & 1,3 (silagem de milho) & 1,3 (cana-de-açúcar) & 2,0 (cana-de-açúcar) & 2,7 (cana-de-açúcar) \\
\hline Farelo de algodão $38 \%$ & 49,87 & 41,66 & 18,48 & 8,04 \\
\hline Farelo de trigo & 42,30 & 53,60 & 78,32 & 89,42 \\
\hline Ureia + sulfato de amônio (9:1) & 3,63 & 0,00 & 0,00 & 0,00 \\
\hline Mistura mineral $^{1}$ & 4,20 & 4,74 & 3,20 & 2,53 \\
\hline Total & 100,00 & 100,00 & 100,00 & 100,00 \\
\hline
\end{tabular}

${ }^{1}$ Sal comum; fosfato bicálcico; calcário calcítico; flor de enxofre; sulfato de zinco; sulfato de manganês; iodato de potássio, sulfato de cobre; sulfato de cobalto. 
Tabela 2 - Composição nutricional da silagem de milho, da cana-de-açúcar e dos concentrados

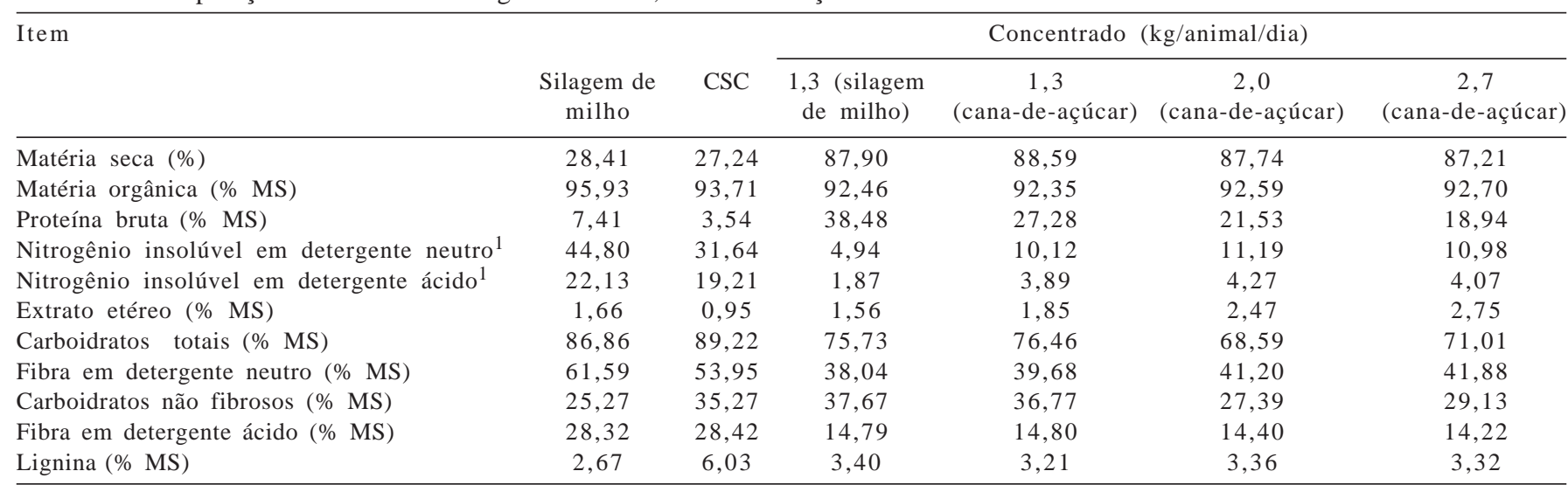

${ }^{1}$ Em porcentagem do nitrogênio total.

CSC = cana-de-acúcar sem correção.

As dietas foram ofertadas duas vezes ao dia, metade por volta das 8 horas e metade por volta das 15 horas, na forma de mistura completa efetuada no momento do fornecimento da alimentação.

O experimento constou de 21 dias de adaptação às dietas, no qual os animais receberam tratamento contra endo e ectoparasitas e vitamina ADE injetável, e três períodos experimentais de 28 dias, perfazendo um total de 84 dias para a coleta de dados e avaliação do desenvolvimento dos animais. No início e no final do experimento e a cada período de 28 dias, após jejum de sólidos de 12 horas, os animais foram submetidos à pesagem individual. Para melhor caracterização do desenvolvimento corporal, aferiram-se também a cada período o perímetro torácico e as alturas de cernelha e garupa.

As novilhas foram alojadas em baias individuais cobertas, com comedouros individuais de concreto e bebedouros automáticos, com $8,0 \mathrm{~m}^{2}$ de área $\left(5,6 \mathrm{~m}^{2} \mathrm{com}\right.$ piso cimentado e $2,4 \mathrm{~m}^{2}$ de área para descanso), na qual foi utilizada cepilho de madeira como cama. As baias foram limpas diariamente e as camas trocadas sempre que necessário.

Diariamente foram feitas pesagens das quantidades dos alimentos fornecidos e das sobras de cada animal para estimativa do consumo de matéria seca. O consumo era ajustado para permitir aproximadamente $10 \%$ de sobras. Durante o período experimental, foram feitas amostragens dos alimentos e das sobras, que foram acondicionadas em sacos plásticos e congeladas para posteriores análises. Ao final de cada período de 28 dias, essas amostras foram misturadas, retirando-se uma amostra composta por animal.

Na metade do segundo período experimental, foi feita a coleta de fezes durante seis dias consecutivos, de 26 em 26 horas, diretamente no reto dos animais. As fezes foram acondicionadas em sacos plásticos, que foram devidamente etiquetados e guardados em congelador. Ao final do período de coletas, as amostras de fezes foram pré-secas e moídas, retirando-se uma amostra composta por animal, com base no peso seco de cada subamostra. Também foram retiradas amostras de sobras e alimentos fornecidos durante esse período de coleta de fezes.

A estimativa da excreção fecal foi feita utilizando-se a fibra em detergente ácido indigestível (FDAi) como indicador interno, segundo adaptação da técnica descrita por Cochran et al. (1986). Nesse procedimento as amostras de alimentos, sobras e fezes foram colocadas em sacos de Ankon (Filter bag F57) e incubadas no rúmen por 144 horas.Em vez da digestibilidade in vitro sugerida por Cochran et al. (1986), o material remanescente da incubação foi previamente lavado com água e, em seguida, submetido à extração com detergente ácido, e o resíduo considerado fibra em detergente ácido indigestível.

As amostras de cana-de-açúcar, silagem de milho, concentrado, sobras e fezes foram pré-secas em estufas de ventilação forçada a $65^{\circ} \mathrm{C}$ durante 72 horas. Em seguida, foram homogeneizadas e processadas em moinho tipo Willey com peneira de malha de $1 \mathrm{~mm}$. As análises da composição em matéria seca (MS), matéria orgânica (MO), compostos nitrogenados totais, fibra em detergente neutro (FDN), fibra em detergente ácido (FDA), lignina, extrato etéreo (EE), compostos nitrogenados $(\mathrm{N})$ insolúveis em detergente neutro (NIDN) e em detergente ácido (NIDA) foram realizadas segundo procedimentos descritos por Silva \& Queiroz (2002). Os compostos nitrogenados nãoproteicos foram determinados conforme Licitra et al. (1996), enquanto os teores de carboidratos totais (CT) foram calculados segundo Sniffen et al. (1992): CT = 100 - (\%PB $+\% \mathrm{EE}+\%$ Cinzas) e os teores de carboidratos não-fibrosos $(\mathrm{CNF})$, obtidos pela fórmula $\mathrm{CNF}=\mathrm{CT}-\mathrm{FDN}$. 
Os nutrientes digestíveis totais (NDT) foram calculados segundo Weiss (1999), pela equação: NDT (\%) = PBD + FDND + CNFD + 2,25 EED, em que PBD = proteína bruta digestível; FDND = fibra em detergente neutro digestível; CNFD = carboidratos não-fibrosos digestíveis e EED = extrato etéreo digestível.

No 83ํㅡ dia do experimento, aproximadamente 4 horas após a alimentação matinal, foram coletadas amostras de sangue de todos os animais, por punção na veia coccígea, utilizando-se tubo de ensaio com gel separador e acelerador de coagulação. Logo após a coleta, as amostras de sangue foram centrifugadas ( 2.000 rpm por 15 minutos) para obtenção de amostras de soro sanguíneo, que foram acondicionadas em recipientes de vidros devidamente identificados e congeladas para posteriores análises de ureia.

A determinação da ureia no soro sanguíneo (NUS) foi realizada segundo o método diacetil modificado (kits comerciais Labtest).

O líquido ruminal foi coletado utilizando-se sonda esofágica, segundo Ortolani (1981), para determinação do pH e da concentração de amônia, nos tempos zero (imediatamente antes da alimentação) e três horas após a alimentação matinal do 84을 dia de experimento. O líquido ruminal foi filtrado em gaze e o $\mathrm{pH}$ medido imediatamente por meio de peagâmetro digital. Após a determinação do pH, retirou-se uma alíquota de $40 \mathrm{~mL}$ de líquido ruminal, que foi transferida para um recipiente de vidro devidamente identificado, contendo $1 \mathrm{~mL}$ de $\mathrm{HCl}$ (1:1). A amostra foi congelada a $-20^{\circ} \mathrm{C}$ para posterior análise de nitrogênio amoniacal.
Os compostos nitrogenados amoniacais do líquido ruminal foram determinados por adaptação do método de Kjeldahl, omitindo-se a fase de digestão. O líquido de rúmen foi descongelado e centrifugado a $1.000 \mathrm{x}$ g, por 15 minutos. Retirou-se uma alíquota de $2 \mathrm{~mL}$, do sobrenadante, transferiu-se para tubo de ensaio, adicionando-se em seguida água destilada e $15 \mathrm{~mL}$ de hidróxido de potássio (2N). Após a adição de $\mathrm{KOH}$, o tubo foi levado imediatamente ao aparelho destilador. A amostra de líquido de rúmen foi destilada em $20 \mathrm{~mL}$ de ácido bórico, sendo o volume do destilado de aproximadamente $100 \mathrm{~mL}$. Posteriormente, procedeu-se à titulação com $\mathrm{HCl}(0,005 \mathrm{~N})$, conforme técnica de Fenner (1965), adaptada por Vieira (1980).

Os resultados foram submetidos à análise de variância e ao teste de média (Tukey) utilizando-se o programa SAEG, versão 8.1 (UFV, 2000), com nível de 5\% de significância.

\section{Resultados e Discussão}

Os consumos de matéria seca (em kg/dia; \% PV e g/kg ${ }^{0,75}$ ), matéria orgânica, proteína bruta e fibra detergente neutro (kg/dia) não diferiram entre as dietas experimentais (Tabela 3) e, quando determinados em porcentagem do peso vivo, foram próximos ao valor médio de $2,55 \%$ do peso vivo preconizado pelo NRC (2001). Alguns trabalhos têm evidenciado diminuição no consumo de matéria seca com o aumento da participação da cana-de-açúcar nas dietas de novilhas e vacas em lactação (Pires et al., 1999; Correa et al., 2003; Mendonça et al., 2004), o que pode ser explicado pela maior quantidade de fibra detergente neutro

Tabela 3 - Consumos médios diários de nutrientes de dietas à base de silagem de milho e cana-de-açúcar

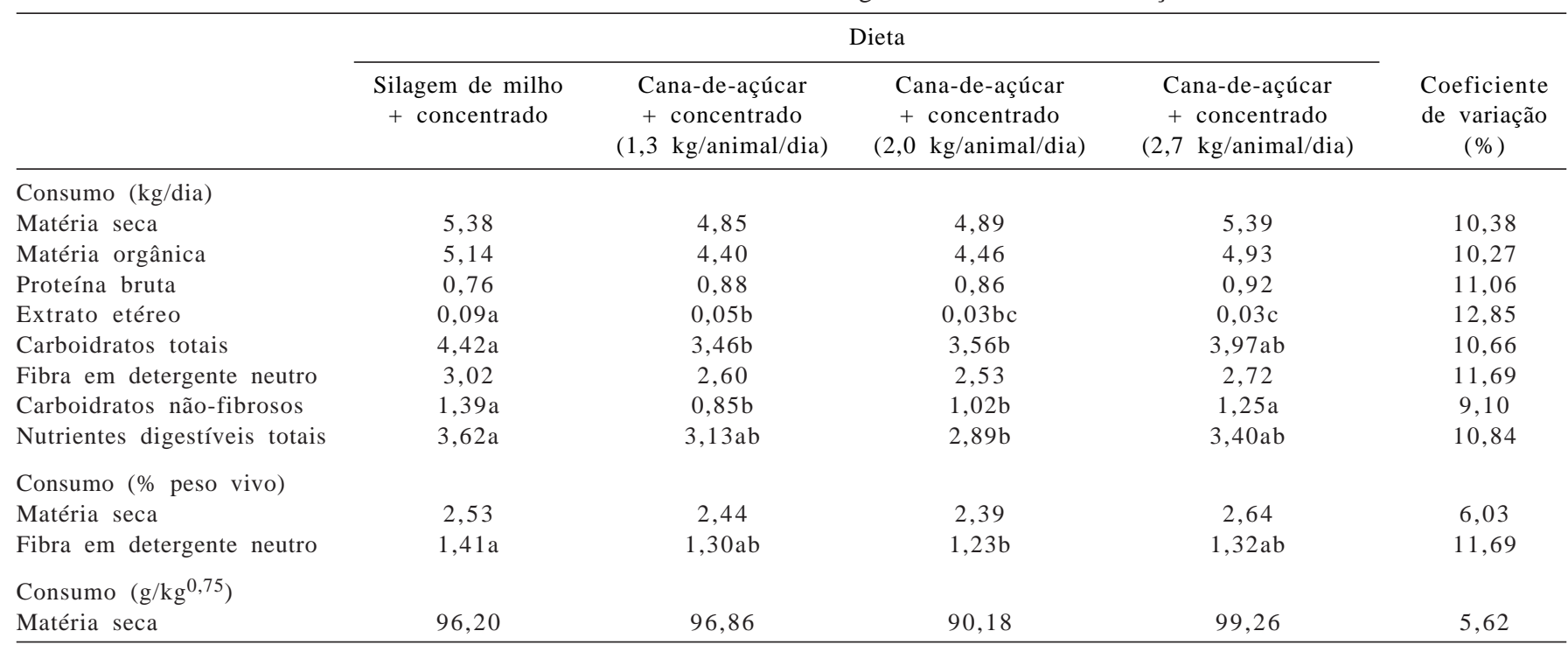

Médias seguidas de mesmas letras na mesma linha não diferem $(\mathrm{P}>0,05)$ pelo teste Tukey. 
indigestível e pela menor taxa de digestão da fração fibrosa potencialmente digestível, que aumentam o tempo de permanência da fibra não digerida no rúmen, reduzindo a taxa de passagem pelo trato gastrointestinal e interferindo negativamente no consumo de matéria seca (Allen, 2000; Landell et al., 2002).

Nos animais alimentados com as dietas à base de canade-açúcar, apesar de não ter ocorrido diferença estatística, independentemente da forma que foi expresso, o consumo de matéria seca apresentou elevação numérica conforme aumentou a participação do concentrado na dieta. Segundo Rodrigues (1999), o aumento do uso de ração concentrada em dietas à base de cana-de-açúcar por meio da mudança na relação volumoso:concentrado pode proporcionar maior aporte de matéria orgânica digestível, aumentando a concentração de energia e diminuindo a concentração de fibra, conseqüentemente, há maior consumo de matéria seca para atender seus requerimentos energéticos.

O maior consumo de extrato etéreo $(\mathrm{P}<0,05)$ foi observado nos animais que receberam as dietas contendo silagem de milho como volumoso, o que provavelmente foi ocasionado pelo baixo percentual de extrato etéreo na composição das dietas à base de cana-de-açúcar.

Os consumos de carboidratos totais e carboidratos não-fibrosos $(\mathrm{P}<0,05)$ da dieta à base de silagem de milho foram maiores que daquelas com cana-de-açúcar e concentrado nos níveis de 1,3 e 2,0 kg/animal/dia, mas não diferiram dos obtidos com nível de concentrado de 2,7 kg/animal/dia.

A dieta contendo silagem de milho possibilitou também maior $(\mathrm{P}<0,05)$ consumo médio de fibra em detergente neutro, o que possivelmente pode ser justificado pelo maior teor de fibra em detergente neutro médio da silagem de milho em relação à cana-de-açúcar.

O consumo de fibra em detergente neutro, quando expresso em porcentagem de peso corporal (\%PV), foi menor $(\mathrm{P}<0,05)$ para a dieta à base de cana-de-açúcar (2,0 kg/concentrado). Independentemente da dieta experimental, o consumo de fibra em detergente neutro foi superior ao valor proposto por Mertens (1985) para capacidade ótima de consumo de animais em crescimento, que é de $1 \%$ do peso vivo. Outros autores também encontraram consumo de fibra em detergente neutro superior ao proposto por Mertens (1985), para fêmeas leiteiras em crescimento (Teixeira et al., 2007).

Todas as dietas com cana-de-açúcar atenderam às exigências de proteína bruta, enquanto aquela à base de silagem de milho apresentou pequeno déficit (Tabela 4). As dietas com cana-de-açúcar e concentrado nos níveis de 1,3, 2,0 e 2,7 kg/animal/dia apresentaram déficit de -0,42; -0,66; e $-0,15 \mathrm{~kg}$, respectivamente, no consumo de nutrientes digestíveis totais. $\mathrm{Na}$ dieta com $2,7 \mathrm{~kg} /$ concentrado/dia, apesar do déficit de $4,2 \%$ em relação à exigência de nutrientes digestíveis totais, foi alcançado o objetivo proposto, de ganho de peso diário de $0,800 \mathrm{~kg} / \mathrm{dia}$.

Não foram verificadas diferenças $(P>0,05)$ nos coeficientes de digestibilidade aparente da matéria seca, matéria orgânica, carboidratos não fibrosos e no teor de nutrientes digestíveis totais entre as dietas (Tabela 5).

Não foram observadas diferenças nos coeficientes de digestibilidade da proteína bruta das dietas à base de canade-açúcar, que foram maiores $(\mathrm{p}<0,05)$ que os da proteína bruta da dieta à base de silagem de milho. Carvalho et al.(1997) também não encontraram efeito dos níveis de concentrado sobre o coeficiente de digestibilidade da proteína bruta de dietas à base de cana-de-açúcar.

O coeficiente de digestibilidade do extrato etéreo da dieta à base de silagem de milho foi maior $(\mathrm{P}<0,05)$ que o da dieta à base de cana-de-açúcar e concentrado no nível de $2 \mathrm{~kg} / \mathrm{animal} /$ dia. Apesar de não ter sido observada diferença entre a dieta à base de silagem de milho e aquelas à base de cana-de-açúcar e concentrado nos níveis de 1,3 e 2,7 kg/ animal/dia, houve pequena diferença numérica, de 8,48 e 8,32 , respectivamente, nas digestibilidades. Isso provavelmente foi ocasionado pelo maior consumo de extrato etéreo na dieta com silagem de milho.

Tabela 4 - Exigências de proteína bruta (PB) e nutrientes digestíveis totais (NDT), segundo o NRC (2001), para novilhas com 220 kg de peso vivo com ganhos de peso de $0,800 \mathrm{~kg} / \mathrm{dia}$

\begin{tabular}{|c|c|c|c|c|c|}
\hline \multirow[t]{3}{*}{ Item } & \multicolumn{5}{|c|}{ Dieta } \\
\hline & \multirow[t]{2}{*}{ Exigências } & \multirow{2}{*}{$\begin{array}{l}\text { Silagem de milho }+ \\
\text { concentrado }\end{array}$} & \multicolumn{3}{|c|}{ Cana-de-açúcar } \\
\hline & & & $1,3 \mathrm{~kg} /$ animal/dia & $2,0 \mathrm{~kg} /$ animal/dia & $2,7 \mathrm{~kg} / \mathrm{animal} / \mathrm{dia}$ \\
\hline NRC (2001) & - & - & - & - & - \\
\hline Proteína bruta $(\mathrm{kg} / \mathrm{dia})^{*}$ & 0,77 & 0,76 & 0,88 & 0,86 & 0,92 \\
\hline Diferença & - & $-0,01$ & $+0,11$ & $+0,09$ & $+0,15$ \\
\hline Nutrientes digestíveis totais (kg/dia)* & 3,55 & 3,62 & 3,13 & 2,89 & 3,40 \\
\hline Diferença & - & $+0,07$ & $-0,42$ & $-0,66$ & $-0,15$ \\
\hline
\end{tabular}

* Valores expressos em kg/dia. 
Tabela 5 - Coeficientes médios de digestibilidade aparente dos nutrientes e teores de nutrientes digestíveis totais (NDT) obtidos para as dietas experimentais

\begin{tabular}{|c|c|c|c|c|c|}
\hline & \multicolumn{4}{|c|}{ Dieta } & \multirow[b]{2}{*}{$\begin{array}{l}\text { Coeficient } \\
\text { de variação } \\
(\%)\end{array}$} \\
\hline & $\begin{array}{l}\text { Silagem de milho } \\
+ \text { concentrado }\end{array}$ & $\begin{array}{l}\text { Cana-de-açúcar } \\
\text { + concentrado } \\
(1,3 \mathrm{~kg} / \text { animal/dia })\end{array}$ & $\begin{array}{c}\text { Cana-de-açúcar } \\
+ \text { concentrado } \\
(2,0 \mathrm{~kg} / \text { animal/dia })\end{array}$ & $\begin{array}{c}\text { Cana-de-açúcar } \\
+ \text { concentrado } \\
(2,7 \mathrm{~kg} / \text { animal/dia })\end{array}$ & \\
\hline Matéria seca & 65,02 & 63,91 & 59,28 & 62,37 & 5,99 \\
\hline Matéria orgânica & 66,89 & 63,85 & 59,55 & 62,73 & 6,34 \\
\hline Proteína bruta & $62,93 b$ & $77,07 \mathrm{a}$ & $74,13 a$ & $74,11 \mathrm{a}$ & 6,56 \\
\hline Fibra em detergente neutro & $64,38 a$ & $55,90 \mathrm{ab}$ & $50,65 b$ & $56,06 \mathrm{ab}$ & 8,73 \\
\hline Carboidratos não-fibrosos & 72,96 & 73,87 & 68,87 & 69,34 & 14,87 \\
\hline Nutrientes digestíveis totais & 67,20 & 63,88 & 59,54 & 62,64 & 6,32 \\
\hline
\end{tabular}

Médias seguidas de mesma letra na mesma linha não diferem ( $\mathrm{P}>0,05)$ pelo teste Tukey.

O coeficiente de digestibilidade da fibra em detergente neutro da dieta à base de silagem de milho foi maior $(\mathrm{P}<0,05)$ que o daquela à base de cana-de-açúcar com concentrado no nível de 2,0 kg/animal/dia. Apesar de não ter sido observada diferença entre a dieta com silagem de milho e aquelas com cana-de-açúcar e concentrado nos níveis de 1,3 e $2,7 \mathrm{~kg} /$ animal/dia, houve diferença numérica na digestibilidade, que foi de 8,48 e 8,32, respectivamente. As reduções no coeficiente de digestibilidade da fibra em detergente neutro nas dietas com cana-de-açúcar podem ser atribuídas à maior participação de lignina na fibra em detergente neutro da cana-de-açúcar em relação à silagem de milho, contribuindo assim para redução na digestibilidade da fibra em detergente neutro. Segundo Van Soest (1994), a lignina é o principal componente da parede celular que limita a digestão dos carboidratos estruturais no rúmen. Assim, elevados teores desse composto podem limitar o uso da cana-de-açúcar, refletindo em menor digestibilidade da fração fibrosa.

A dieta à base de cana-de-açúcar e com o maior nível de concentrado (2,7 kg/animal/dia) proporcionou ganho de peso médio diário igual ao daquela à base de silagem de milho. Resultado semelhante tem sido observado em vacas leiteiras quando alimentadas com dietas à base de canade-açúcar e maiores níveis de concentrado (Costa et al., 2005; Oliveira et al., 2007). Quando comparadas as dietas à base de cana-de-açúcar, não se observou diferença no ganho médio diário (kg/dia), entretanto, biologicamente não se pode desconsiderar o maior ganho de peso obtido com o maior nível concentrado (2,7 kg/animal/dia). Maior ganho médio diário $(\mathrm{P}<0,05)$ foi observado para a dieta à base de silagem de milho em relação àquelas à base de cana-de-açúcar e com os menores níveis de concentrado (1,3 e 2,0 kg/dia).

Entre as dietas com cana-de-açúcar, o ganho médio diário, de 0,60 kg/dia, dos animais que receberam concentrado no nível de 1,3 kg/dia, para idade ao primeiro parto próxima de 27 meses é satisfatório para as condições de criação semi-intensiva no Brasil.

A altura de cernelha, a altura de garupa e o perímetro toráxico, expressos em cm/dia não diferiram $(\mathrm{P}>0,05)$ entre as dietas experimentais (Tabela 6). Os valores de altura de cernelha e altura de garupa foram próximos aos encontrados

Tabela 6 - Peso inicial e final e ganhos de parâmetros barimétricos obtidos para as dietas à base de silagem de milho e cana-de-açúcar

\begin{tabular}{|c|c|c|c|c|c|}
\hline & \multicolumn{4}{|c|}{ Dieta } & \multirow[b]{2}{*}{$\begin{array}{c}\text { Coeficiente } \\
\text { de variação } \\
(\%)\end{array}$} \\
\hline & $\begin{array}{l}\text { Silagem de milho } \\
+ \text { concentrado }\end{array}$ & $\begin{array}{c}\text { Cana-de-açúcar } \\
\text { + concentrado } \\
(1,3 \mathrm{~kg} / \text { animal/dia })\end{array}$ & $\begin{array}{c}\text { Cana-de-açúcar } \\
\text { + concentrado } \\
(2,0 \mathrm{~kg} / \text { animal/dia })\end{array}$ & $\begin{array}{c}\text { Cana-de-açúcar } \\
\text { + concentrado } \\
(2,7 \mathrm{~kg} / \text { animal/dia })\end{array}$ & \\
\hline Peso vivo inicial (kg) & 178,00 & 179,00 & 178,4 & 175,80 & 11,95 \\
\hline Peso vivo final (kg) & 253,0 & 229,4 & 233,6 & 243,2 & 11,24 \\
\hline Ganhos de peso total (kg) & $75,00 \mathrm{a}$ & $50,50 b$ & $55,25 b$ & $67,44 \mathrm{ab}$ & 16,76 \\
\hline Ganhos médios (kg/dia) & $0,892 \mathrm{a}$ & $0,601 \mathrm{~b}$ & $0,657 b$ & $0,802 \mathrm{ab}$ & 16,76 \\
\hline Ganhos médios de altura decernelha total (cm/dia & 0,107 & 0,104 & 0,097 & 0,102 & 19,45 \\
\hline Ganhos médios de altura de garupa (cm/dia) & $0,123 a$ & $0,090 \mathrm{a}$ & $0,097 \mathrm{a}$ & $0,118 \mathrm{a}$ & 17,94 \\
\hline Ganhos médios de perímetro toráxico (cm/dia) & $0,157 a$ & $0,121 b$ & $0,114 b$ & $0,157 a$ & 13,20 \\
\hline Altura de cernelha $(\mathrm{kg} / \mathrm{cm})$ & 8,64 & 6,11 & 6,87 & 8,03 & 21,68 \\
\hline Altura de garupa $(\mathrm{kg} / \mathrm{cm})$ & 7,41 & 6,95 & 6,92 & 6,88 & 18,70 \\
\hline Perímetro toráxico $(\mathrm{kg} / \mathrm{cm})$ & 5,73 & 5,13 & 6,34 & 5,26 & 26,68 \\
\hline
\end{tabular}

Médias seguidas de mesma letra na mesma linha não diferem ( $\mathrm{P}>0,05)$ pelo teste Tukey. 
por Teixeira et al. (2007) com fêmeas leiteiras em crescimento. Os resultados de altura de cernelha $(\mathrm{cm})$ ao final do experimento $(117,07 \mathrm{~cm})$ estão na faixa de $117,0 \mathrm{~cm}$ preconizada por James (2001) para raça Pardo-Suíça, da mesma idade, em pesquisa sobre os padrões de desenvolvimento e requerimento de nutrientes em novilhas leiteiras nos Estados Unidos.

Não houve influência $(\mathrm{P}>0,05)$ das dietas no ganho de peso vivo, na altura de cernelha e de garupa nem no perímetro toráxico. A Associação Brasileira de Criadores de Gado da Raça Holandesa (ABCGH) estabelece padrões de crescimento diferenciados, com maiores valores para rebanhos de maior potencial de produção de leite. Entretanto, a relação altura de cernelha $(\mathrm{kg} / \mathrm{cm})$ é igual para todos os rebanhos (6 kg de peso corporal/cm de ganho de altura de cernelha) para que os animais não fiquem baixos e gordos. Neste trabalho, a relação altura de cernelha encontrada para a dieta à base de cana-de-açúcar com os menores níveis de concentrado (1,3 e 2,0 kg/animal/dia) foi próxima à proposta pela Associação de Criadores de Gado da Raça Holandesa e tendeu a aumentar conforme o forneci-mento de concentrado nas dietas à base desse volumoso. Esse comportamento também foi observado nos animais alimentados com a dieta à base de silagem de milho. Resultados semelhantes têm sido encontrados por outros autores com o aumento de nitrogênio não-proteico ou da relação energia/proteína na dieta (NRC, 2001).

Não houve diferença entre a dieta à base de silagem de milho e aquelas contendo cana-de-açúcar, e nem entre as dietas à base de cana-de-açúcar, para os valores de $\mathrm{pH}$ antes da alimentação e 3 horas após (Tabela 7). Os valores de $\mathrm{pH}$, em ambos os tempos de coleta, mantiveram-se na faixa de atividade normal do rúmen, 6,7 $\pm 0,5$ (Van Soest, 1994).

A concentração de amônia ruminal imediatamente antes da alimentação não diferiu entre a dieta com silagem de milho e aquelas com cana-de-açúcar. Nos animais alimentados com as dietas à base de cana-de-açúcar, os resultados observados foram superiores aos encontrados Costa et al. (2005) e Oliveira et al.(2007) utilizando dietas à base de cana-de-açúcar para vacas de leite.

As concentrações de amônia ruminal 3 horas após a alimentação foram menores para a dieta $(\mathrm{P}<0,05)$ à base de silagem de milho, que numericamente apresentou menor consumo de proteína. Resultado contrário foi observado em vacas leiteiras por Pires et al. (1999), que encontraram maiores valores de $\mathrm{N}-\mathrm{NH}_{3}$ para uma dieta com cana-de-açúcar em substituição à silagem de milho e atribuíram o resultado à maior utilização de nitrogênio não-proteico para síntese microbiana nas dietas com cana, em virtude do maior teor de carboidratos rapidamente fermentáveis no rúmen.

Os resultados obtidos neste trabalho para a concentração ruminal de $\mathrm{N}-\mathrm{NH}_{3}$ três horas após a alimentação estão acima do mínimo sugerido por Satter \& Slyter (1974), de $5 \mathrm{mg} / \mathrm{dL}$, e, no caso das dietas com cana-de-açúcar, estão acima do mínimo de 15 mg/dL sugerido por Leng \& Nolan (1984) para máximo crescimento microbiano.

A concentração de nitrogênio ureico (NUS) é indicativo do nível proteico e energético da dieta e tem alta correlação positiva com os teores de proteína da dieta e de proteína degradável no rúmen (Broderick \& Clayton, 1997; Chizzotti et al., 2007). A concentração plasmática de ureia em animais recebendo dietas com diferentes níveis de concentrado tem grande importância, pois o consumo de compostos nitrogenados pode variar entre os níveis de concentrado, podendo levar a perdas de proteína, já que esse nutriente é o de maior custo na composição de rações e de maior gasto energético para o animal. Neste estudo, o menor valor de nitrogênio ureico obtido para a dieta à base de silagem de milho não pode ser justificado biologicamente.

Tabela 7 - pH e concentração de $\mathrm{N}-\mathrm{NH}_{3}$ do líquido ruminal após a alimentação

\begin{tabular}{|c|c|c|c|c|c|}
\hline \multirow[b]{2}{*}{$\begin{array}{l}\text { Tempo após a } \\
\text { alimentação (horas) }\end{array}$} & \multicolumn{4}{|c|}{ Dieta } & \multirow[b]{2}{*}{$\begin{array}{c}\text { Coeficiente } \\
\text { de variação } \\
(\%)\end{array}$} \\
\hline & $\begin{array}{l}\text { Silagem de milho } \\
+ \text { concentrado }\end{array}$ & $\begin{array}{l}\text { Cana-de-açúcar } \\
+ \text { concentrado } \\
(1,3 \mathrm{~kg} / \text { animal/dia })\end{array}$ & $\begin{array}{c}\text { Cana-de-açúcar } \\
+ \text { concentrado } \\
(2,0 \mathrm{~kg} / \mathrm{animal} / \mathrm{dia})\end{array}$ & $\begin{array}{c}\text { Cana-de-açúcar } \\
+ \text { concentrado } \\
(2,7 \mathrm{~kg} / \mathrm{animal} / \mathrm{dia})\end{array}$ & \\
\hline \multicolumn{6}{|c|}{$\mathrm{pH}$} \\
\hline 0 & 7,06 & 7,13 & 7,08 & 7,05 & 2,01 \\
\hline 3 & 6,61 & 6,57 & 6,47 & 6,31 & 3,02 \\
\hline
\end{tabular}

Médias seguidas de mesma letra na mesma linha não diferem $(\mathrm{P}>0,05)$ pelo teste Tukey. 


\section{Conclusões}

A cana-de-açúcar corrigida e com maior participação de concentrado, próxima da relação volumoso:concentrado de 45:55, na base seca da dieta, pode ser utilizada em substituição à silagem de milho em sistemas de produção de leite com idade ao parto próxima dos 24 meses. Em dietas com cana-de-açúcar, o nível de concentrado de $1,3 \mathrm{~kg} /$ animal/dia, correspondente à relação volumoso:concentrado de 75:25, com base na matéria seca da dieta, é uma opção viável para as condições de criação semi-intensiva no Brasil com idade ao primeiro parto projetada para os 27 meses.

\section{Referências}

ALLEN, M.S. Effects of diet on short-term regulation of feed intake by lactating dairy cattle. Journal of Dairy Science, v.83, p.1598-1624, 2000.

ANDRADE, M.A.F.; PEREIRA, M.N. Performance of hostein heifers on fresh sugarcane as the only dietary forage. Journal of Dairy Science, v.82, p.91, 1999. (Suppl. 1),

BALSALOBRE, M.A.A.; FERNANDES, R.A.T.; SANTOS, P.M. Corte e transporte da cana-de-açúcar para consumo animal. In: PEIXOTO et al. (Ed.) SIMPÓSIO SOBRE NUTRIÇÃO DE BOVINOS, 7., Piracicaba, 1999. Alimentação Suplementar. Anais... Piracicaba: FEALQ, 1999. p.7-26.

BRODERICK, G.A.; CLAYTON, M.K. A statistical evaluation of animal and nutritional factors influencing concentrations of milk urea nitrogen. Journal of Dairy Science, v.80, n.11, p.2964-2971, 1997.

CARVALHO, A.U.; VALADARES FILHO, S.C.; SILVA, J.F.C. et al.. Níveis de concentrado em dietas de zebuínos.1.Consumo e digestibilidade aparente. Revista Brasileira de Zootecnia, v.26, n.5, p.986-995, 1997.

CHIZZOTTI, M.L.; VALADARES FILHO, S.C.; VALADARES, R.F.D. et al. Consumo, digestibilidade e excreção de uréia e derivados de purinas em vacas de diferentes níveis de produção de leite. Revista Brasileira de Zootecnia, v.36, p.138-146, 2007.

COCHRAN, R.C.; ADAMS, D.C.; WALACE, J.D. et al. Predicting digestibility of different diets with internal markers: evaluation of four potential markers. Journal of Animal Science, v.63, p.1476-1483, 1986.

CORREA, C.E.S.; PEREIRA, M.N.; OLIVEIRA, S.G. et al. Performance of Holstein cows fed sugarcane or corn silages of different grain textures. Scientia Agricola, v.60, n.4, p.621-529, 2003.

COSTA, M.G.; CAMPOS, J.M.S.; VALADARES FILHO, S.C. et al. Desempenho produtivo de vacas leiteiras alimentadas com diferentes proporções de cana-de-açúcar e concentrado ou silagem de milho na dieta. Revista Brasileira de Zootecnia, v.34, n.6, p.2437-2445, 2005 (supl.).

GALLO, P.C.S.; PEREIRA, M.N.; ANDRADE, M.A.F. Effect of dietary sugarcane concentration on heifer growth. Journal Dairy Science, v.83, p.144, 2000. (Suppl. 1).

HOFFMAN, P. C. Optimun body Size of Holstein replacements heifers. Journal of Animal Science, v.75, p.836-845, 1997.

JAMES, R. E. Growth standards and nutrient requerents for dairy heifers - weaning to calving. Advances in Dairy Technology, v.13, p.63, 2001.

LANDELL, M.G.A.; CAMPANA, M.P.; RODRIGUES, A. A. et al. A variedade IAC-862480 como nova opção de cana-de-açúcar para fins forrageiros: manejo de produção e uso na alimentação animal. Boletim Técnico IAC, n.193, 36p, 2002.

LENG, R.A.; PRESTON, T.R. Sugar cane for cattle production: present constraints perspectives and research priorities. Tropical Animal Production, n.1, p.1-22, 1976.

LICITRA, G.; HERNANDEZ, T.M.; VAN SOEST, P.J. Standardization of procedures for nitrogen fractionation of ruminant feeds. Animal Feed Science Technology, v.57, p.347-358. 1996.

MAGALHÃES, A.L.R.; CAMPOS, J.M.S.; VALADARES FILHO, S.C. et al. Cana-de-açúcar em substituição à silagem de milho em dietas para vacas em lactação: desempenho e viabilidade econômica. Revista Brasileira de Zootecnia,v.33, n.5, p.1292-1302, 2004.

MENDONÇA, S.S.; CAMPOS, J.M.S.; VALADARES FILHO, S.C. et al. Consumo, digestibilidade aparente, produção e composição do leite e variáveis ruminais em vacas leiteiras alimentadas com dietas à base de cana-de-açúcar. Revista Brasileira de Zootecnia, v.33, n.2, p.481-492, 2004.

MERTENS, D.R. Factors influencing feed intake in lactating cows: From theory to application using neutral detergent fiber. In: GA NUTRItion CONFERENCE, 46., 1985, Athens. Proceedings... Athens: University of Georgia, 1985. p.1-18.

NATIONAL RESEARCH COUNCIL - NRC. Nutrient requirements of dairy cattle. 7.ed. Washington, D.C.: National Academic Press, 2001. 381p.

OLIVEIRA, A.S.; CAMPOS, J.M.S.; VALADARES FILHO, S.C. et al. Substituição do milho por casca de café ou de soja em dietas para vacas leiteiras: consumo, digestibilidade dos nutrientes, produção e composição do leite. Revista Brasileira de Zootecnia, v.36, n.4, p.1172-1182, 2007 (supl.).

ORTOLONI, E.L. Considerações técnicas sobre ouso da sonda esofágica na colheita do suco de rúmen de bovinos para mensuração do $\mathrm{pH}$. Arquivo da Escola de Veterinária da UFMG, v.33, n.2, p.269-275, 1981.

PIRES, A.V.; SIMAS, J.M.C.; ROCHA, M.H.M. et al. Efeito da substituição da silagem de milho pela cana-de-açúcar na consumo de matéria seca, parâmetros ruminais, produção e composição do leite de vacas holandesas. In: REUNIÃO ANUAL DA SOCIEDADE BRASILEIRA DE ZOOTECNIA, 36., 1999, Porto Alegre. Anais... Porto Alegre: SBZ, 1999. (CD-ROM).

PRESTON, T.R. Nutritional limitations associated with the feeding of tropical forages. Journal of Animal Science, v.54, n.4, p.877-883, 1982.

RODRIGUES, A.A. Potencial e limitações de dietas a base de cana-de-açúcar e uréia para recria de novilhas e para vacas em lactação. In: SIMPÓSIO MINEIRO DE NUTRIÇÃO DE GADO DE LEITE, 2., 1999, Belo Horizonte. Anais... Belo Horizonte, 1999, p.65-75

SATTER, L.D.; SLYTER, L.L. Effect of ammonia concentration on rumen microbial production in vitro. British Journal of Nutrition, v.32, p.199-208, 1974.

SILVA, J.D.; QUEIROZ, A.C. Análise de alimentos (métodos químicos e biológicos). 3.ed. Viçosa, MG: Editora UFV, 2002. $235 p$.

SNIFFEN, C.J.; O’CONNOR, J.D.; VAN SOEST, P.J. et al. A net carbohydrate and protein system for evaluating cattle diets: II. Carbohydrate and protein availability. Journal of Animal Science, v.70, p.3562-3577, 1992.

SOUZA, D.P.; CAMPOS, J.M.S.; VALADARES FILHO, S.C. et al. Comportamento ingestivo, consumo e digestibilidade de nutrientes, produção e composição do leite de vacas alimentadas com silagem de milho ou cana-de-açúcar com caroço de algodão. Revista Brasileira de Zootecnia, v.38, n.10, p.2053-2062, 2009.

TEIXEIRA, R.M.A.; CAMPOS, J.M.S.; VALADARES FILHO, S.C. et al. Consumo, digestibilidade e desempenho de novilhas 
alimentadas com casca de café em substituição à silagem de milho. Revista Brasileira de Zootecnia, v.36, n.4, p.968-977, 2007.

UNIVERSIDADE FEDERAL DE VIÇOSA - UFV. Departamento de Engenharia Agrícola. Estação meteorológica. Dados climáticos. Viçosa, MG: UFV, 1997. 86p.

UNIVERSIDADE FEDERAL DE VIÇOSA - UFV. SAEG - Sistema de Análises Estatísticas e Genéticas. Versão 8.0, Viçosa, MG, 2000. 142p. (Manual do usuário).
VAN SOEST, P.J. Nutritional ecology of the ruminant. 2.ed. Ithaca: Cornell University, 1994. 476p.

VIEIRA, P.F. Efeito do formaldeído na proteção de proteínas e lipídios em rações para ruminantes. 1980. 98f. Tese (Doutorado em Zootecnia) - Universidade Federal de Viçosa, Viçosa, MG.

WEISS, W.P. Energy prediction equations for ruminant feeds. In: CORNELL NUTRITION CONFERENCE FOR FEED MANUfACTURERS, 61., 1999, Ithaca. Proceeding... Ithaca: Cornell University, 1999. p.176-185. 